\title{
Despojos de psique. Trauma, inscripción y archivo en Tentativa Artaud de R. Kay
}

\section{Remains of Psyche. Trauma, inscription and archiv in Ronald Kay's Tentativa Artaud}

Francisco Vega C.

Universidad Autónoma de Madrid - Conicyt/Chile

franciscovega.c@gmail.com

\section{Resumen}

En octubre de 1974 se ejecuta la "primera fase" de Tentativa Artaud de Ronald Kay. En principio, diríase que la obra traza espacios de resistencia corporal contra el disciplinamiento que impone la dictadura. Más hondamente, no obstante, la obra complejizará ese enclave mediante una estratificada "arqueología de la memoria". Pues, en efecto, toda esa "primera ejecución" es registrada por diversos aparatos técnicos, formando un "microarchivo" que será expuesto diferidamente (el año 2008) en el Museo Nacional de Bellas Artes, convertido así en macro-archivo. Tentativa Artaud, por tanto, no es ni fácilmente fechable ni tampoco cómodamente localizable - pues incorpora virtualmente todos los sitios con los que se ha relacionado. Mediante esa conmoción generalizada, Tentativa Artaud tensiona las criteriologías de la teoría del arte vernácula y, al mismo tiempo que determina como "fundamentalmente inestable" cualquier registro histórico, problematiza la fundamentación técnica de la inscripción mnémica.

Palabras clave: trauma, inscripción, archivo, memoria, técnica.

\begin{abstract}
In October of 1974 the "first phase" of Tentativa Artaud by Ronald Kay was executed. In principle, it could be said that the work traces spaces of corporal resistance against the discipline imposed by the dictatorship. More deeply, however, the work will complicate that enclave through a stratified "archeology of memory". Indeed, all that "first execution" is recorded by various technical devices, forming a "micro-file" that will be exposed in a deferred way (2008) in the MNBA - converted into macro-archive. Tentative Artaud, therefore, is neither easily dateable nor comfortably locatable -since it incorporates virtually all the sites with which it has been related. Through this generalized commotion, Tentativa Artaud questions the criteriologies of the vernacular art theory and, at the same time that it determines as "fundamentally unstable" any historical record, problematizes the technical foundation of the mnemic inscription.
\end{abstract}

Keywords: trauma, inscription, archive, memory, technique. 


\section{Umbral}

Ya sea por la diversidad de vetas de lectura que promueve -las potencias del cuerpo, la relación entre superficie de inscripción, obra y acontecimiento, la interrogación sobre la temporalidad de la vanguardia, la representación del horror, el enclave técnica-memoria-, o por la densa capa de operatorias que despliega -acción de arte, instalación, land art- o, asimismo, por la polifonía que hace despuntar entre acontecimientos artísticos, teóricos y políticos -el teatro de la crueldad, Beuys, Fluxus, Vostell, la DINA, la CNI, entre otros-, Tentativa Artaud, de Ronald Kay, debe considerarse una obra sin duda fundamental. Al tiempo que pionera (atendiendo al carácter señero de su factura respecto de las labores del arte chileno de la época ${ }^{1}$ ), la particular intensidad de la obra, diríase en una primera instancia, está signada por la transitividad generalizada que despliega entre esos diversos soportes, acciones, citas y materiales. Paradoja, de tal suerte, de una obra cuyo posible asidero de ejecución y exégesis debe pesquisarse en la deslocalización, desestabilización y diferimiento del conjunto de criterios y coordenadas analíticas tradicionales ${ }^{2}$.

Se trata, en efecto, de una "obra" que desbarata cualquier nominación simple. ¿Dónde se ejecuta la obra? ¿Cuál es su sitio o lugar? ¿El Departamento de Estudios Humanísticos de la Universidad de Chile (DEH), la DINA o el Museo Nacional de Bellas Artes? ¿Desde qué género o marco categorial abordarla? ¿Acción de arte, instalación, body art? ¿Cuándo se realiza o despliega, en 1974, en 2008, o en el tránsito entre esas datas? Son todas preguntas que, en su motivación más concreta y directa, y esto sin jugarse en su formulación ninguna intencionalidad hermética ${ }^{3}$, Tentativa Artaud viene a desbaratar en su compleja dinámica composicional. Pues no podemos ni datar fácilmente la obra, ni tampoco localizarla, ni siquiera servirnos, al menos cómodamente, de nociones al uso como "campo expandido". Se trata, por cierto, de una "dificultad", o de un desajuste de las convenciones, que ha venido ensayando ejemplarmente todo el trabajo de Kay, en sus múltiples e interconectadas ramificaciones, desde la poesía, el video-arte o el ensayo poético-filosófico, guardando, para todas estas clasificaciones (incluida la de ejemplaridad), las obligadas reservas. Como veremos, el continuo desplazamiento que se ejercita en Tentativa Artaud de las categorías que intentan delimitar su emergencia -su "emplazamiento"-, se ve incrementado por la compleja trama espacio-temporal ínsita a la obra, y, como otra membrana de esa misma señal,

1 Para un análisis del arte realizado por las mismas fechas en Chile, los Textos sobre arte de E. Lihn ofrecen un aporte fundamental (2008). Fundamentales también resultan El revés de la trama (2010) y los diversos volúmenes de Ensayos sobre artes visuales en Chile que ha venido compilando y editando el Centro de Documentación de las Artes Visuales (CEDOC) desde el año 2011.

2 En el catálogo de la exposición de Patricio Rojas Motivo de Yeso, Kay y Dittborn abordan las obras ahí expuestas bajo la signatura, aquí también elocuente, de lo "definitivamente transitorio" (1978).

3 Análogamente a lo postulado por Rancière respecto de Mallarmé (10), se puede decir enfáticamente que nada de hermetismo hay en Kay. Se trataría, más bien, en su caso, de una recodificación de la relación imagen, palabra y soporte, mediante un ejercicio material que, de hecho, contraría la práctica del hermetismo, un procedimiento que el mismo Kay sitúa bajo la estela del poeta francés (Kay, Vostell s/n). 
por la densa noción de archivo que refiere, siendo en ese quiasma, precisamente, donde debe su potencia crítica tantearse.

No se está muy descaminado, de tal forma, si se determina que en Tentativa Artaud es hallable una dificultad estructural, que impide, o al menos dificulta, el mantenimiento de las convenciones o la inercia de la definiť̌o clásica (en tanto establecimiento de límites y/o fines) y que, por esa tensión que despliega, puede considerarse afín a las contemporáneas filosofías de la diferencia y la virtualidad (en cuyo seno, como es sabido, el nombre de Artaud no es uno entre otros). Pero junto a esa dificultad, y en gran medida suscitada por ella, es hallable otra desazón en torno a la Tentativa, específicamente respecto a su omisión en el debate estético promovido por la teoría del arte nacional. En primer lugar, debe consignarse que la obra está ausente prácticamente de la totalidad de los estudios estéticos e historiográficos dedicados al arte de (neo)vanguardia en Chile. Su estatuto y alcances, en efecto, no han suscitado ni un solo intento de exégesis, y tampoco su nombre, siquiera, es mencionado en las múltiples derivas de análisis que abordan ya sea el problema de la vanguardia en Chile o los diversos filones temáticos que, anteriormente, indicamos como ejemplarmente suscitados por Tentativa Artaud.

Dicha laguna, indudablemente, arraiga en múltiples circunstancias fácticas que dificultaron acceder más allá de su umbral y contornos. Entre ellas, debe consignarse el estatuto parcialmente académico de la obra, como también, y como un factor altamente relevante, la ausencia de una exposición institucional hasta el año $2008^{4}$. Es menester apuntar dichas consideraciones para no suponer que el acceso a Tentativa Artaud ha estado vedado por la inexistencia en el ámbito nacional de desarrollos analíticos consistentes ${ }^{5} \mathrm{o}$, como apuntamos antes, por la cerrazón tenaz de la obra en sí misma o la promoción de un lenguaje esotérico o reificado.

Sin embargo, y más intensamente, el escaso contacto mantenido con la obra se fundamenta también en la serie de desafíos que impone a las teorías que a ella quieran aproximarse, en la anomalía que parece irradiar. Pues, en efecto, aquellas doctrinas que quieran ampararse en los géneros o estilos (performance, instalación, $v$. gr.) hallarán un trabajo donde la "yuxtaposición” no permite ninguna distinción clara, mientras que aquellas que busquen resguardo en la cronología toparán con una torsión permanente de las temporalidades. Finalmente, las que busquen delimitar su despliegue mediante criterios analíticos precisos - la ciudad como museo expandido, el archivo del arte y el arte como archivo, la configuración fotográfica del mirar, entre otros- encontrarán en Tentativa Artaud una interacción de todos esos vectores de análisis en una trama conceptual particularmente densa y, stricto sensu, difícil de analizar, y esto no por una

4 Asimismo, debe tenerse en cuenta que Kay residirá desde el '81 hasta el 2009 en Wuppertal, hecho que dificultó un acercamiento más fluido a su trabajo general.

5 Difícilmente hoy se podría mantener la diagnosis que Oyarzún, en su fundamental "Arte en Chile, de veinte, treinta años", refería respecto de la tradición crítica en Chile (213), y esto precisamente gracias a los trabajos desarrollados, entre otros autores, por el mismo Oyarzún. 
cuestión acumulativa o de grado. Con Tentativa Artaud, dicho esto, es posible referir una suerte de "inserción de lo anómalo" en las formaciones discursivas, ya se trate de historiografía del arte, de estética o del problema de la representación del horror. Dicha anomalía complejiza el archivo del arte y el archivo de la catástrofe, y, como veremos, lo hace mediante una práctica auto-referencial de archivística.

\section{Vestigios}

Luego de su regreso desde Konstanz, uno de los seminarios impartidos por Kay en el DEH estará dedicado a los escritos de Artaud, y es precisamente como actividad complementaria y "práctica" de dicho seminario - denominado Signometraje- que se ejecutará "parcialmente" la Tentativa Artaud (Kay, Tentativa s/n). Entre los motivos de la obra se encuentra la idea de acceder a la teoría de Artaud a partir de una materialización que se juzga como requerida por la misma doctrina artaudiana, y que supone una suerte de "excarnación", una materialización corporal de aquello que se ha reflexionado teoréticamente. La obra se lleva a cabo en octubre de 1974, cumplido poco más de un año del Golpe de Estado, es decir, teniendo aún muy cerca el origen del acontecimiento traumático, pero a una distancia suficiente, aunque embrionaria, como para bosquejar una cartografía de sus gravedades.

Hasta este momento, la obra conocida de Kay consiste en un conjunto de poemas que han aparecido en diversas revistas y antologías - como Anales de la Universidad de Chile o la valdiviana Trilce-, de modo tal que Tentativa Artaud puede entenderse aún como expresión de los primeros tanteos de Kay, y como el germen inaugural de su obra artística no literaria. Es relevante consignar este dato pues echa luz sobre un aspecto altamente decidor, a saber: el horizonte y meollo de la obra de Kay está fundamentalmente determinado, desde sus primicias, por la idea de catástrofe. La catástrofe golpista, en efecto, es cifra fundamental de Tentativa Artaud, pero se trata, incluso, de un evento traumático que para el propio Kay tiene un alcance más intenso. Y es que él, en efecto, puede articular el Golpe de Estado en su memoria -en su "archivo" subjetivo, digamos- con la catástrofe que ya, siendo niño, le tocó presenciar cuando los aviones aliados bombardearon brutalmente su ciudad natal, Hamburgo, forzando a su familia a escapar.

La ignominia de los aviones bombardeando La Moneda, dicho de otro modo, constituye para Kay una cita de una destrucción precedente, la de Hamburgo (magistralmente estudiada por Sebald en su Historia natural de la destrucción $\left.(2015)^{6}\right)$, cuestión

6 Conviene destacar que ya en esos poemas tempranos de Kay la muerte aparece como una figura recurrente. A guisa de ejemplo, ténganse en cuenta los poemas "Arte poética" y "Corral 1966" ("Poemas" 143 y 150); o, ya en las Variaciones ornamentales, "Hysterical tears" (29). Téngase en cuenta, asimismo, que otro de los seminarios impartidos por Kay estuvo dedicado a The waste land de Eliot (Kay, Circuito 10). No deben olvidarse, por su parte, las referencias a la dimensión temporal como "Sangre de Cronos" o "lágrimas de Cronos" (Ibíd. 19), una idea indisociable, en Kay, del 
FIGURA 1

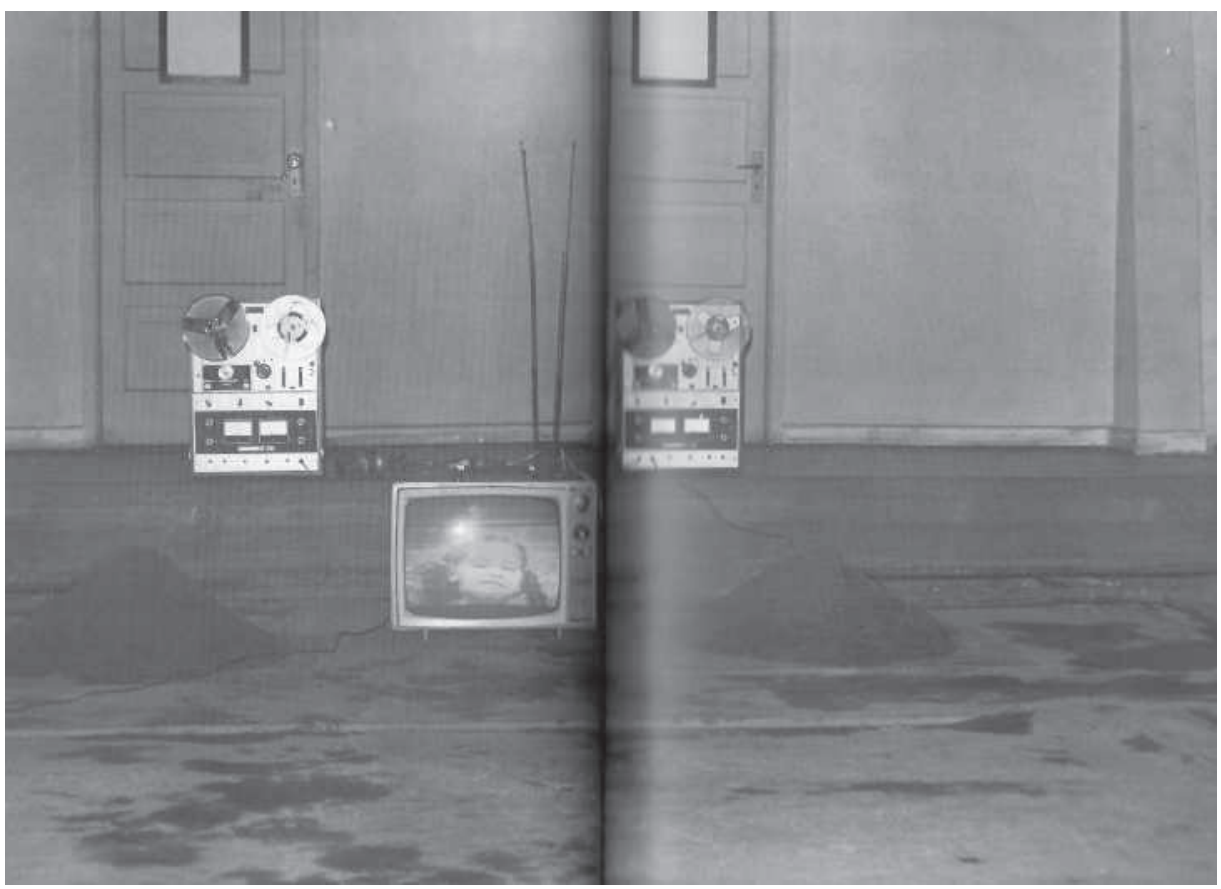

Imagen interior del catálogo Tentativa Artaud. 2008.

que suscitará en él una especial sensibilidad respecto al archivo del acontecimiento, los desgarros del trauma y el continuum catastrófico de la Historia. Una idea que es posible colegir incluso desde una pesquisa somera de sus diversos trabajos. Téngase en cuenta, para consignar algunos antecedentes, la vinculación emocional que Kay establece en Circuito cerrado entre la "inhumanidad nazi” y el Golpe de Estado (11) o, en el mismo libro, la referencia a una "catástrofe permanente, que siempre ya ha ocurrido" (27).

La data de surgimiento de Tentativa Artaud, decíamos, es octubre de 1974. El lugar escogido es el DEH, y más específicamente el ático deshabitado del inmueble ubicado en Av. República 475. El lugar, según se explica en el "catálogo" de la Tentativa Artaud, se juzga particularmente adecuado por estar a salvo del trajín del día a día, y por ofrecer una infraestructura "desnuda", sin ningún tipo de mobiliario -teniendo, por ejemplo, aún sin revestir el radier o recubrir el vigamen-, lo que ofrecerá las idóneas "coordenadas metafísicas" para "una obra artaudiana" (Kay, Tentativa s/n). (Figura 1)

problema de la memoria, respecto al cual la traducción de "Mnemosyne", de Hölderlin, constituye una referencia importante (Kay, "La mirada..." s/n). La idea de catástrofe permanente (Katastrophe in Permanenz), cabe destacarlo, es extraída del parágrafo 5 de Zentralpark, de Benjamin, que el mismo Kay tradujo (Parque central 2014). 
Aparte de Kay, quien dirige la puesta en escena, participan en ella cuatro personas: la artista visual Catalina Parra, el poeta Raúl Zurita, Eugenio García y el novelista Juan Balbontín. Delante de las dos puertas que llegan al ático, se instalarán dos grabadoras magnetofónicas y, entre ellas, avanzando un poco hacia delante, un televisor frente al cual se sentarán en fila los participantes, uno al lado del otro. El espacio ocupado será rodeado por algunos micrófonos conectados a una grabadora (cuya función será registrar los sonidos emitidos durante la jornada), y se depositarán en el suelo diversos utensilios que se usarán posteriormente, entre ellos cinta adhesiva, gasa, una pala, tierra y una radiografía. A cada uno de los cuatro participantes, Kay les dará instrucciones de acción, mientras él, por su parte, registrará todo lo acontecido con una cámara fotográfica. Todos se sacarán los zapatos, exceptuando Zurita, quien se acostará frente al televisor y será cubierto con polietileno y cinta adhesiva.

Paralelamente, Zurita hará uso de unos audífonos conectados a otra grabadora, escuchando así, solo él, los sonidos que se emitirán desde ella, específicamente el registro de la locución "RATARA", que ha grabado él mismo en una sesión anterior. Los otros miembros, por su parte, quedarán vinculados a Zurita mediante cintas adhesivas que llegan a sus cabezas, previamente vendadas con gasa. Al finalizar la audición del archivo de su propia locución del fonema RATARA, Zurita proferirá desgarradoramente un grito que repetirá otro previamente grabado. Kay, mientras tanto, cubrirá la pantalla del TV con la radiografía y apagará su sonido, dejando así desfilar solo las imágenes ahora recubiertas. El mismo Kay, asimismo, vinculará a los cuatro miembros que están en el suelo con el TV mediante una línea de tierra que ha desperdigado con una pala, y que pasará por encima del cuerpo de Zurita y por encima de los pies de los restantes miembros. Al escuchar el grito de Zurita, finalmente, los demás participantes se sumarán con más gritos, mientras se liberan de sus ataduras de gasa, scotch y tierra. Como señalamos, Kay registrará todo el proceso con fotografías, las que conformarán un micro-archivo que incluirá también el sonido archivado por la grabadora (Figura 2).

Barruntado sucintamente el marco general de la obra, su lugar de emplazamiento y su tiempo, conviene consignar que Tentativa Artaud es desarrollada, atendiendo al señalamiento explícito de Kay, bajo el influjo de Beuys y Vostell (Kay, Tentativa s/n) ${ }^{7}$. Teniendo en cuenta que la obra es referida por el mismo Kay como una suerte de ready-made, también el impulso de Duchamp debe añadirse a su campo de fuerzas. En términos generales, puede decirse que la comprensión de la Tentativa Artaud como ready-made es efectuada atendiendo a la consabida profanación que ejecuta de las

7 En el catálogo de Tentativa Artaud se mencionan también como determinantes los nombres de Neruda y Rilke. De este último, Kay citará el celebérrimo primer verso de la primera de las Duineser Elegien: “¿Quién, si yo gritase, me escucharía de entre el orden de los ángeles?" Como veremos, la apelación de Rilke al orden angélico será modulada en la obra de Kay mediante la referencia a lo virtual y lo espectral: "El grito permanece", se dice en el catálogo, pero mientras en Rilke permanecerá como remanente metafísico de una subjetividad desgarrada, en Kay permanecerá gracias a la virtualidad de los aparatos técnicos de registro. 


\section{FIGURA 2}

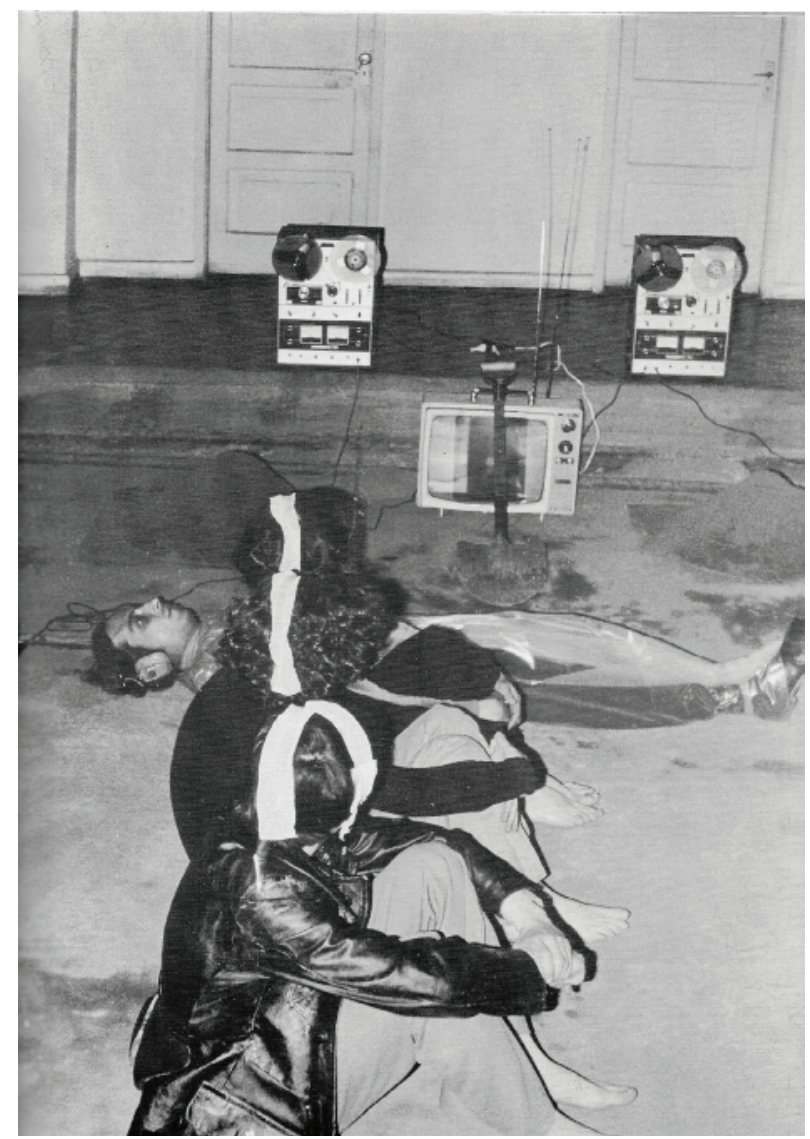

Imagen interior del Catálogo Tentativa Artaud. 2008.

categorías artísticas tradicionales (creador, institución, recepción, $v . g r$.), y particularmente por su cuestionamiento de la relación arte/vida. Sin embargo, teniendo en cuenta el conocimiento que Kay tiene de la crítica que Fluxus, en general, y Vostell, en particular, realizan a Duchamp (a saber, el de haber hecho "vida del arte" sin hacer "arte de la vida" (Vostell s/n), se puede conjeturar que es más bien otro el aspecto que atrae a Kay al trabajo duchampiano. Un antecedente al menos así lo sugiere. En el ensayo "Lecciones de analogía", Kay señala sentirse particularmente atraído a Le Grand Verre, y específicamente a la caracterización que hiciera Duchamp de la obra como Delay in Glass (retardo en vidrio) (42). De tal modo, no es tanto la idea de profanación la que atrae a Kay, sino la potencialidad del ready-made, su capacidad de insertarse en cadenas de significación histórica diversas. Lo que importa a Kay del ready-made, en otros términos, no es otra cosa que la virtualidad que parece serle inherente.

La influencia de Artaud, por su parte, se hará sentir en diversos aspectos de la Tentativa Artaud y el trabajo general de Kay. Atendiendo simplemente a las citas 
que aparecen en el libro-catálogo, es evidente que las premisas de El teatro y su doble serán determinantes. Sin embargo, no se necesita ni conocer esas citas ni el contenido doctrinario de Signometraje para atisbar la centralidad de Artaud. En efecto, esto se hace evidente ya en la misma ejecución de la Tentativa, específicamente en la importancia que otorga al desgarro corporal, pero también en su tenaz crítica antirepresentacional (desplegada mediante el desmontaje de la relación voz/texto). De igual modo, y primordialmente, el influjo del teatro de la crueldad es hallable en el alcance psico-social que se le adjudica a esa crítica anti-representacional: en Artaud, como es sabido, se trata del combate contra la peste (Artaud, "Le Theatre..." 7), mientras que en la Tentativa, por su parte, comparecerá metonímicamente también como lucha contra la degradación dictatorial. Baste consignar al respecto el señalamiento dado en el catálogo, que indica que con la Tentativa Artaud no se busca sino promover una resistencia a la "parálisis psíquica" que creó el Golpe (Kay, Tentativa s/n).

Igual o aún más penetrante será la influencia ejercida por el artista germano Wolf Vostell, a quien Kay conoció personalmente en Alemania en un período de fuerte absorción de las nuevas corrientes artísticas europeas. De Vostell, Kay rescatará diversos motivos que expresan gran parte de sus preocupaciones medulares, entre ellos la indagación recurrente de nuevos procedimientos formales y su continua e incesante yuxtaposición. No obstante, será el problema de la devastación política el principal polo de atracción que vincule a Kay con Vostell ${ }^{8}$, y, paralelo a ello, una comprensión que hace del arte un enclave particularmente profundo para lidiar con el trauma y la catástrofe. Entre muchas otras, se puede atisbar esa indicación en el trabajo de Vostell Depression Endogène, del año '75. Se trata de una multi-instalación en la que una serie de televisores y aparatos radiofónicos son recubiertos con hormigón, y mantenidos así durante un extenso lapso de tiempo, con el objetivo de visualizar la acumulación de polvo, el deterioro de los materiales y, principalmente, el surgimiento entre las ruinas de nuevas formas de vida, como insectos o pájaros.

En Depression Endogène apreciamos una yuxtaposición de la crítica de la reificación, promovida por los mass media, con la profanación institucional duchampiana, radicalizada al mismo tiempo bajo la exhortación Fluxus de un "devenir arte de la vida”. Esta divisa, como es sabido, determina también la obra de Beuys ("Jeder Mensch ist ein Künstler") y de Kaprow, cuyas reflexiones sobre el nuevo arte tendrán un lugar destacado en el catálogo de la exposición de Vostell El huevo (Figura 3), realizada en Chile el '77 bajo la gestión y curaduría del propio Kay. En este mismo catálogo,

8 En su libro Vostell, Kay señala que el punto de partida para el artista alemán no sería sino la idea, promovida por Benjamin, de "catástrofe permanente" ( $\mathrm{s} / \mathrm{n})$. Es de destacar, asimismo, la centralidad que posee el motivo del avión en la obra de Vostell El huevo, una figura importante también para Kay, y que es posible apreciar, asimismo, en otro tratamiento de la catástrofe como es Der Engel der Geschichte, de Anselm Kiefer (expuesta paradójicamente en el Museo de Israel). Respecto al análisis de la relación entre Vostell y Kay, conviene no perder de vista que el apartado "El tiempo que se divide", contenido en Del espacio de acá (2009), es un fragmento del ensayo Das Objektiv der Zeichen, escrito originalmente en 1972 como exégesis de los happenings de Vostell, específicamente su utilización del registro fotográfico (Kay, Vostell s/n). Con todo, como más adelante veremos, las reflexiones de Kay sobre el archivo foto(video)gráfico, aunque emparentadas con Fluxus, deben juzgarse más radicales en sus propósitos y alcances. 
FIGURA 3

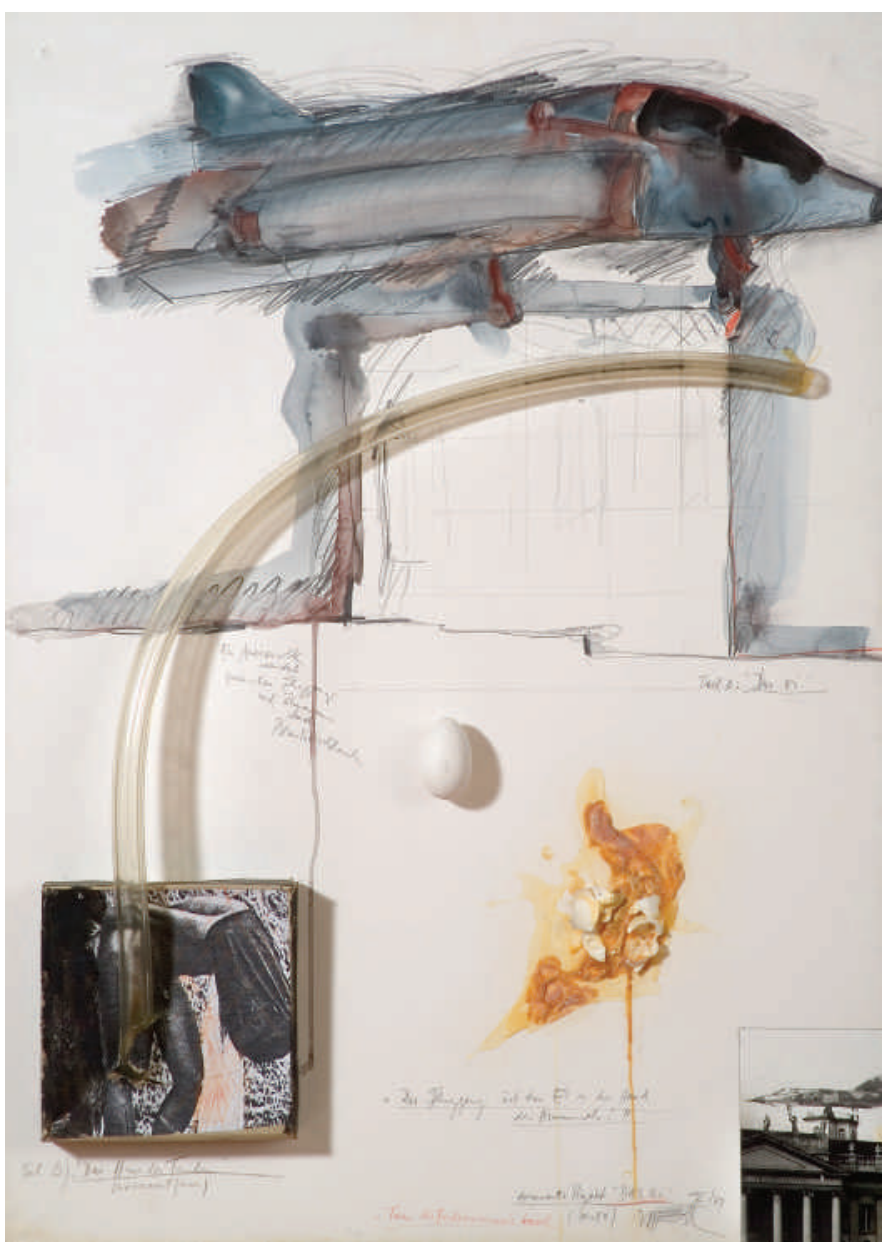

Vostell, Wollf. El huevo (V), 1977. Museo de la Solidaridad Salvador Allende.

Vostell ahondará en la noción de psico-estética, noción de decisiva importancia aquí (en relación a la Tentativa) en cuanto formaliza de modo muy fino la conjunción de la indistinción arte/vida, que recién referimos, con el intento de vivificar los cuerpos desgarrados por la catástrofe socio-política (Vostell s/n).

Todos estos indicios pueden contribuir al esclarecimiento de Tentativa Artaud, aunque no se trata sino de una parte de la obra, y notoriamente la menos decidora, en cuanto en tanto lo fundamental está dado por otro mecanismo, uno que apenas hemos rozado, a saber: el diferimiento de la obra hasta el año 2008, fecha en que se expone ya públicamente el completo registro del '74. Para dilucidar de modo preciso esta operación y sus consecuencias, no obstante, es menester profundizar en otros estratos de la obra. 


\section{Cuerpo/traza fotográfica}

Es posible determinar que el "aquí y ahora" que se afirma en las "acciones de arte" o en la instalación, incluso cuando estas no son registradas por aparatos de reproducción, constituye un modo de aparecer que busca destituir la determinación aurática de la experiencia tematizada por W. Benjamin. En efecto, aunque "kantianamente" sea pertinente precisar que la condición aurática no es propiedad de objetos sino, más bien, marco de experiencia del sujeto de la percepción, puede determinarse que muchas de las prácticas artísticas antes referidas contribuyen al socavamiento aurático en la medida en que funcionan bajo la divisa del "cada vez no es suficiente", opuesto al "de una vez por todas" (Benjamin, Das Kunstwerk 111). Se hace preciso consignar esto en la medida en que se podría cuestionar cómo es que logran conjugarse armónicamente la fugacidad vitalista del "teatro de la crueldad" con las reflexiones de cuño benjaminiano sobre la reproductibilidad, dos de los pilares basales de Tentativa Artaud.

De hecho, y de ahí la mención a este problema, en la misma reflexión de Kay es hallable una aparente fractura que escinde la reproductibilidad archivística (y su diferimiento) de la presencia inmediata de los cuerpos y sensibilidades. En efecto, en "Introducción a la mortalidad" - escrito el ' 88 y referido al Tanztheater de Pina Bausch- ahonda Kay en una idea de "memoria colectiva" que, aunque se cuida de fundamentar en un arché o una tierra a-histórica, recurre continuamente a una metaforología organicista (incluida una valoración ambigua de la “autogénesis" (30-31)) marcada por el lenguaje aurático y el valor de culto. Al menos en términos latos -ya que convendría profundizar en los diversos estratos que pueda contener esa lógica organicista ensayada a partir de las premisas de Artaud $^{9}$-debe señalarse que no es del todo fácil la adaptación de esas premisas del ensayo sobre Bausch con aquellas reflexiones sobre el aparato técnico contenidas en otros múltiples trabajos.

Al respecto, es menester consignar el desplazamiento de la manualidad orgánica por "la mano ortopédica" ensayado en "Proyecciones en dif. esc.:" (219). Como otro ejemplo, debe atenderse a la comprensión emprendida en "El cuerpo que mancha", en el que Kay, al mismo tiempo que revalora -artaudianamente, por cierto- los desechos corporales como vinculación primera entre el hombre y el entorno ${ }^{10}$, no deja

9 Con Benjamin (Das Kunstwerk 113-114), se estaría tentado de señalar cómo también en Artaud -en sus análisis sobre cine- se hace uso de un lenguaje mágico para juzgar un fenómeno postaurático, a la manera de F. Werfel o A. Gance. Sin embargo, es consabido todo el desplazamiento y reconfiguración que hace Artaud de esa misma terminología, por ejemplo, la brujería y el trance en sus escritos sobre cine ("On the cinema” 65) o la noción de metafísica en El teatro y su doble (“The Theatre...” 7). Un cuestionamiento de la "ontología” artaudiana debería, necesariamente, hacer la prueba de esa resistencia nominalista.

10 Una lectura que sigue esa pista es la ofrecida por Patricio Marchant en "Discurso contra los ingleses", texto leído como presentación de los libros Del espacio de acá, de Kay, y Cuerpo correccional, de N. Richard. El expediente biopolítico, como intentamos sugerir supra., o no es del todo preciso para referir el trabajo de Kay o, al menos, requiere una indagación más vasta que permita avizorar las diferentes "políticas del cuerpo" ensayadas por al arte chileno en dictadura. 
de cuestionar al final, subrepticiamente, la distinción tradicional que ha escindido máquina y cuerpo, y que podría encontrar resolución si se entiende la máquina como una proyección corporal y, a la inversa, al cuerpo como matriz primordial del dispositivo mecánico (Kay, Del espacio 32).

Aunque no solo en esos estudios, que tratan más enfáticamente el problema, se pone en juego la reflexión de Kay sobre el cuerpo. En la serie visual Interneteadas - parte de su trabajo artístico más tardío- aparte de ejecutarse yuxtaposiciones visuales disruptivas, a la manera del Atlas Mnemosyne de Warburg, se intenta también cuestionar la disciplina corporal que gobierna tanto la búsqueda manual en el computador (con el cierre y apertura de ventanas) como la visualización estandarizada de imágenes en la web. En este sentido, el interés de Kay no está restringido al significado y la referencia de las imágenes, sino que incorpora también su aspecto significante y performativo ${ }^{11}$. Una idea, esta de la atención material y corporal, que es posible rastrear -y fundamentar- ya en la investigación de postgrado de Kay, Die Rhetorik des Blickes.

Las referencias antes pesquisadas permiten colegir que la corporalidad primariamente promovida por Kay no consiste en el restablecimiento de fuerzas entendidas como dadas. Por el contrario, Kay sugiere ahí que el cuerpo se encuentra siempre, por principio, haciendo máquina con diversos aparatajes y complementos maquínicos. Patente resulta este aserto en "El tiempo que se divide", en el que Kay hará suya, aunque con modulaciones, la noción benjaminiana de inconsciente óptico. Encontramos también esta idea ejemplarmente desarrollada en Variaciones ornamentales a partir de dos operaciones concretas. En primer lugar, la escritura general constituye un pastiche del lenguaje estandarizado de los medios de comunicación, lo que permite caracterizar al libro como una suerte de aparato de grabación que recodifica los flujos del lenguaje masivo ${ }^{12}$. En segundo lugar, la hipótesis basal que dirige el libro -a saber, la configuración mediática, tele-visiva, del lenguaje- es recreada performativamente en el libro al situar el campo discursivo (los versos) al interior del campo televisivo, específicamente los fotogramas de una película de cine B (Kay, Variaciones s/n) ${ }^{13}$.

Desde el marco de legibilidad antes esbozado, se puede determinar que la noción benjaminiana de inconsciente óptico (y la idea de una determinación técnica de la percepción) tendrá un hondo calado en la obra de Kay, desde Variaciones ornamentales hasta Interneteadas, y también, y esto es aquí lo esencial, en la Tentativa Artaud, en

11 Esta atención a lo performativo resulta decisivo para comprender el interés de Kay en la cartografía. Al respecto, véase el ensayo "Clío" o el apartado "Escena primera" de "Proyecciones en dif. esc.:" (229). Un tratamiento reciente de la performatividad de las imágenes puede consultarse en Der Bildakt (Bredekamp 2015).

12 En las Variaciones ornamentales, dirá Kay, el lenguaje escrito es fotografiado (Kay, Circuito 23). Teniendo en cuenta este rasgo, caracterizará también el poemario como una obra pop (Ibíd. 26).

13 Sobre la "reproductibilidad como origen", podemos decir, son múltiples las pistas dadas por Kay. Solo de Variaciones ornamentales son elocuentes, entre otros, los poemas "La infancia de Ícaro" y "Entrar en materia". Expresivo al respecto también resulta el poema "A little step", contenido en Deep freeze (73), en la medida en que a Kay no le es prioritario (como aún late en "Moon landing" de Auden) el cuestionamiento de la pérdida de misterio de la luna ante la llegada del hombre, sino cómo ese mismo suceso mantuvo al planeta entero frente al televisor. 
cuyo plexo de operaciones, como es notorio, comparece tanto el trabajo de intervención corporal como la problemática técnica de la inscripción y registro del acontecimiento. De tal suerte, aunque en principio se distinga el motivo del cuerpo y el de la traza mecánica, se trata siempre de un enclave operativo indisociable en la obra de Kay ${ }^{14}$.

Por otra parte, como sugerimos, la idea de un cuerpo determinado por los aparatos de reproducción interactúa con las hipótesis de Die Rhetorik des Blickes, a saber: el reconocimiento de que el proceso técnico de impresión configura una escritura sin modelo previo, sin origen y sin falta, en la medida en que la disposición significante de la tipo-grafía (absolutamente decisiva en la obra "editorial" de Kay ${ }^{15}$ ) suscita un campo inédito de significación. El propio Kay ha argumentado que su teoría supone un ajuste de cuentas con diversas teorías contemporáneas de la escritura ("Conversaciones con Ronald Kay"), entre ellas la de Derrida, que juzga insuficiente desde el momento en que, teniendo como horizonte de análisis a la grafía manual (y no a la mecánica), comprende erradamente a la escritura como copia y secundariedad. Independientemente de lo ajustado de su enjuiciamiento, la importancia crucial que tiene este análisis de Kay reside en dos consideraciones: en primer lugar, hace suyos los rendimientos más intensos tanto de la crítica derrideana del logocentrismo (el reconocimiento de que el significado funciona desde siempre como significante (De la gramatologie 16) como también los de la liberación significante del teatro de la crueldad. En segundo lugar, incorpora una reflexión de lo técnico (a partir del aparato de imprenta) que ni Artaud ni Derrida habrían apreciado exhaustivamente ${ }^{16}$.

En síntesis, mediante este rodeo metafísico-técnico se puede colegir que Tentativa Artaud, a pesar de incorporar un conjunto de premisas del teatro anti-representativo de Artaud (y de Fluxus), modifica sin embargo su doctrina a partir de una lógica de lo virtual y del diferimiento que se resiste a la pureza de las distinciones efectuadas en El teatro y su doble (voz/texto, presencia/ausencia, actor/receptor). En segundo lugar, efectuará esa modificación a partir de una reflexión técnica del registro histórico, que entiende como indisociables la memoria y los soportes materiales de inscripción. Como ahora veremos, en la inserción de esa virtualización y de ese diferimiento técnico, explícitamente señalado por Kay en el catálogo de la Tentativa Artaud, se enhebran también una serie de diversos efectos estéticos e histórico-políticos.

14 El cuerpo, por tanto, debe siempre lidiar con ese complejo maquínico si pretende buscar un restablecimiento de sus fuerzas o una metamorfosis de sus capacidades. En "Proyecciones en dif. esc.:", lo veremos, se trata de no desligar nunca esos dos enclaves. "Trazar un cuadro clínico", se afirma en este ensayo, refiriendo la traza y el cuadro a una doble significación: trazar como escritura (clínica) psicoanalítica y como grafía; cuadro como escena psíquica y como dispositivo técnico-artístico (231).

15 Desde la revista Manuscritos a los catálogos creados con el grupo V.I.S.U.A.L vemos ensayado un trabajo donde imagen y texto difuminan sus contornos inmediatos y se acoplan en un espacio de significación más vasto, en el que la letra no es mero complemento explicativo de la imagen, ni esta ejemplo ilustrativo de aquella. "Rewriting", contenido en Manuscritos, constituye el primer bosquejo de esa operación.

16 Se sabe que Derrida, en De la gramatología, advierte que la pregunta por la escritura precede a la pregunta por la técnica (18). Bernard Stiegler (324 y ss), cabe destacarlo, ha llamado la atención más recientemente sobre lo que juzga es un tratamiento deficitario de la técnica en el pensamiento de Derrida. 


\section{Tra(u)ma}

Kay registra con fotografías y grabaciones de audio toda la acción del '74. Todo ese material será a fines de ese año guardado, "archivado", permaneciendo así en estado latente por 34 años, hasta que es expuesto públicamente en una muestra en el Museo Nacional de Bellas Artes (MNBA) el 2008. De tal suerte, en principio puede decirse que la obra parte en 1974 y culmina después de 34 años, incorporando en su devenir el conjunto amplio de sus materiales, soportes e instituciones. En la exposición del 2008, con todo, se incorporarán nuevos elementos, específicamente un conjunto de imágenes de la central de escucha que en el inmueble de Av. República 475 hiciera operativa la CNI, luego de la clausura del DEH; y también un video, denominado $\mathrm{La}$ sangre de Cronos (elaborado con las fotos y el audio archivados el '74, una extensa grabación del cuartel de la CNI y también fragmentos de la desgarradora lectura radiofónica de Artaud, en 1947, de Pour en finir avec le jugement de dieu). Algunas imágenes, cabe destacarlo, aparecerán en el catálogo de la exposición en el MNBA, un catálogo que, como constante en el trabajo de Kay, supone mucho más que un registro propedéutico y mediador de la exposición.

En estricto rigor, sin embargo, no es que Tentativa Artaud tenga dos fases, ni tampoco que sea una obra unitaria que dure 34 años. Tampoco se trata de una obra que es ejecutada "de una vez" para ser reabierta en otro momento, ni tampoco de un material que, "potencialmente", espera un momento de emergencia, transportando consigo todos los sitios y materiales con los que se ha vinculado. De cierta manera, Tentativa Artaud articula todo eso junto. No obstante, y de un modo más preciso, su estrategia fundamental debe pesquisarse en el registro o "autoarchivo" de sus propias operaciones. Dicho de otro modo, no tanto en el señalamiento de lo "transitorio", sino en la problematización autorreflexiva de sus propias condiciones de legibilidad. En el despliegue de esa operación, la Tentativa da cuenta de la inestabilidad del acontecimiento, pero también, y de forma más intensa, el reconocimiento de que su inscripción es dependiente de un amplio circuito de soportes técnicos e institucionales. La obra promueve así una suerte de lógica de archivo virtual, una lógica que, a partir de su diferimiento ínsito y de su propia "autocontención" (como archivo que problematiza sus propios marcos de lectura), crea un juego de espejos en el que contenido y continente se contaminan mutuamente, sin permitir una delimitación diáfana de sus zonas de emplazamiento. Pues, en efecto, si el continente institucional (el DEH) que contenía la "primera fase artaudiana" es transformado luego en contenido del MNBA, ¿qué impide pensar que esta última institución se preste a posteriori como contenido a un nuevo relevo sustitutivo ${ }^{17}$

17 Aunque imposible de profundizar aquí, conviene señalar que ese “juego de espejos” debería dialogar con las reflexiones sobre lo sublime, específicamente con lo que Déotte denomina un "sublime de los aparatos" (Déotte 45). 
En ese sentido específico, con la Tentativa se juega una "puesta en abismo" materialista que no puede ser leída bajo el signo de la proliferación de yuxtaposiciones formales ${ }^{18}$, ni tampoco, meramente, bajo la idea del tránsito o la latencia (cardinal en Fluxus ${ }^{19}$ ), en la medida en que no es la consignación de lo viviente como mutabilidad su sello distintivo, sino, más hondamente, el señalamiento de lo factual (y de la herencia) como técnicamente in-formado o, de otro modo, aun, el entendimiento de que no hay contingencia sin institución, como no hay inscripción sin superficie de inscripción dependiente de un complejo aparataje técnico-institucional. Desde esta perspectiva, mediante la lógica limítrofe que suscita, Tentativa Artaud constituye una anomalía que conmociona la cronología histórica y la criteriología tradicional, precisamente al revelar las tensiones que se cobijan en las relaciones a priori/a posteriori, texto/ contexto, representación/presencia, corte/fundación.

Mediante esta estrategia, como se consignó al inicio, con Tentativa Artaud es posible entrever también aporías en el debate estético chileno. En primer lugar, la obra resultaría refractaria al tono "fundacionalista" que late, como ha sido destacado ya por diversos analistas ((Oyarzún 257), (Macchiavello 97)) en el ineludible Márgenes e instituciones, de N. Richard. El trabajo de Kay, en efecto, con la fractura que promueve de las temporalidades, permitiría advertir una cierta prehistoria de lo "avanzado en el arte", sugiriendo con ello un trabajo genealógico atento a las discontinuidades y cisuras. Correlativamente, aunque es cierto que Tentativa Artaud hace suya la crítica artaudiana de la representación, incorpora en ella, como se dijo, una fisura interna que tensiona la distinción representación/presencia, problematizando con el ello la tesitura dilemática entre corte y fundación que parece adoptar el debate promovido entre N. Richard y W. Thayer en torno al Golpe de Estado y la (neo)vanguardia (Thayer, "El Golpe como..."; Richard, Márgenes).

Siguiendo esa misma seña, la Tentativa viene a embrollar también los recortes secuenciales elaborados en la historiografía del arte vernácula, advirtiendo de su estatuto estructuralmente parcial ${ }^{20}$. Asimismo, aparte de subvertir las certezas de la

18 Por esta razón específica, decíamos supra., la conceptualización de Krauss de "campo expandido" (68) no resulta aquí pertinente.

19 Entre muchas otras, son aquí de interés las obras 7000 Eichen, de Beuys, y Salat, de Vostell. Esta última tendrá un gran alcance en la Tentativa, como hace ver el mismo Kay (Vostell s/n). La "latencia", cabe destacarlo, guarda a su vez relación con el problema site/non-site, decisivo también para Kay en tanto incide en su reflexión del "lugar" y del "origen". Un análisis de este problema requeriría interrogar la particular recepción que Kay hace de Heidegger. $\mathrm{Al}$ respecto, cabe destacar que Willy Thayer ha señalado que la obra de Kay es "heideggeriana" (cit. en Galende, Filtraciones II 130), leyendo en esa adscripción una cierta política identitaria. Atendiendo, sin embargo, al cuestionamiento de lo propio que se desarrolla en Circuito cerrado (10), esa interpretación requeriría un balance mucho más exhaustivo. Entre otros materiales de Kay relevantes para este problema, deben tenerse en cuenta el libro Lorenzo Berg, un origen (2014), su trabajo en torno a la etnopoesía de Hubert Fichte y, asimismo, su colaboración como consejero artístico en el film El techo de la ballena, de Raúl Ruiz (1981).

20 Algo advertido por el mismo Oyarzún cuando señala que no puede suponerse una "organicidad teleológica" que enlace la evolución del arte en Chile (Oyarzún 216). Es de destacar también, por cierto, que la misma N. Richard profundizó más tarde en ese tono enfático y "declamativo" de Márgenes antes enunciado (cit. en Galende, Filtraciones I 191). En otro trabajo, asimismo, Richard se refiere a las estrategias discursivas que era preciso adoptar en dictadura (N. Richard, Crítica y política 172), estrategias que indudablemente deben ser consideradas en la exégesis de todo este problema. 
periodización histórica, en Tentativa Artaud se ensaya también un cuestionamiento de los análisis en los que determinadas operatorias formales sirven de marcos trasparentes de delimitación, como la intervención urbana del CADA, el desgarro corporal de la performance en Leppe o la "incardinación" del aparato técnico en el mirar en la obra de Dittborn, esto en la medida en que cuerpo, ciudad y técnica son categorías que en la Tentativa resultan indisociables. Habida cuenta de esto, es posible entrever la lógica virtual de Tentativa Artaud como un ejercicio de cuestionamiento de la propia criteriología, de sus fundamentos y alcances, siendo esto, precisamente, lo que la haría anómala respecto a la cronología, a la clasificación de géneros o tendencias y, también, a la misma vocación de definición de una idea del arte.

Como expresión de este desajuste genealógico que suscita Kay resultan de interés las palabras del artista Patrick Hamilton, quien señaló que, al momento de hacerse pública la Tentativa Artaud el 2008, la intención de Kay no era sino mostrar que «las prácticas neo-vanguardistas ocurrieron antes de la Avanzada» (cit. en Galende, Filtraciones III 35). Por su parte, la desazón estético-ontológica que suscita la obra de Kay puede atisbarse a la vista de una anécdota relevante, expresiva, en parte, de su coeficiente crítico basal. De acuerdo a Kay, habiendo circulado la información de su intención de curatoriar un environment de Vostell en Chile el '77, se le habrían acercado miembros del TAV para conminarlo a no hacerlo, ya que de llevarse a cabo, según ellos, se creería que había libertad en Chile (!) (Kay, Vostell s/n). Dicho relato resulta revelador en cuanto permite contraponer una cierta comprensión del arte, la de Kay, que dinamita las certezas sobre la recepción y función del arte, con otra que parece más segura en la diagnosis de sus funciones y tiempos ${ }^{21}$.

Estos antecedentes son sin duda consustanciales a lo que puede señalarse como la "anomalía Kay", una anomalía que aquí, específicamente en la Tentativa, se cifra en un ensayo de problematización autorreflexiva de sus propias operaciones y condiciones de legibilidad. Pues se trata de una obra que archiva sus materiales y sus soportes (de lectura), suscitando así una arqueología que indaga en sus propios mecanismos de indagación. En ese específico sentido, se opera con la Tentativa no solo una memoria arqueológica, sino también una arqueología de la memoria, entendiendo por tal un trabajo de recolección que atiende no solo a la fragilidad del evento sino también a la fragilidad, más fundamental, de los mecanismos que permitan una comprehensión del mismo. Desde ese reconocimiento, bajo la doble premisa de una memoria radicalmente inestable y en tensión con su afuera, la Tentativa desplegará un trabajo de atesoramiento o recolección donde son indisociables el inconsciente pulsional-que late en todo el trabajo de diferimiento de la obra- y el inconsciente óptico que ha hecho suyo Kay en múltiples pasajes de su quehacer. Esta yuxtaposición, cabe destacarlo, será

21 La anécdota no deja de mantener cierta semejanza con la crítica que Didi-Huberman -también un desestabilizador de las cronologías-, ha esgrimido recientemente contra Rosalind Krauss, argumentando que mientras ella trabaja con una lógica de definiciones, él trabaja sin saber qué es el arte (Didi-Huberman, “Entrevista...” s/n). 


\section{FIGURA 4}

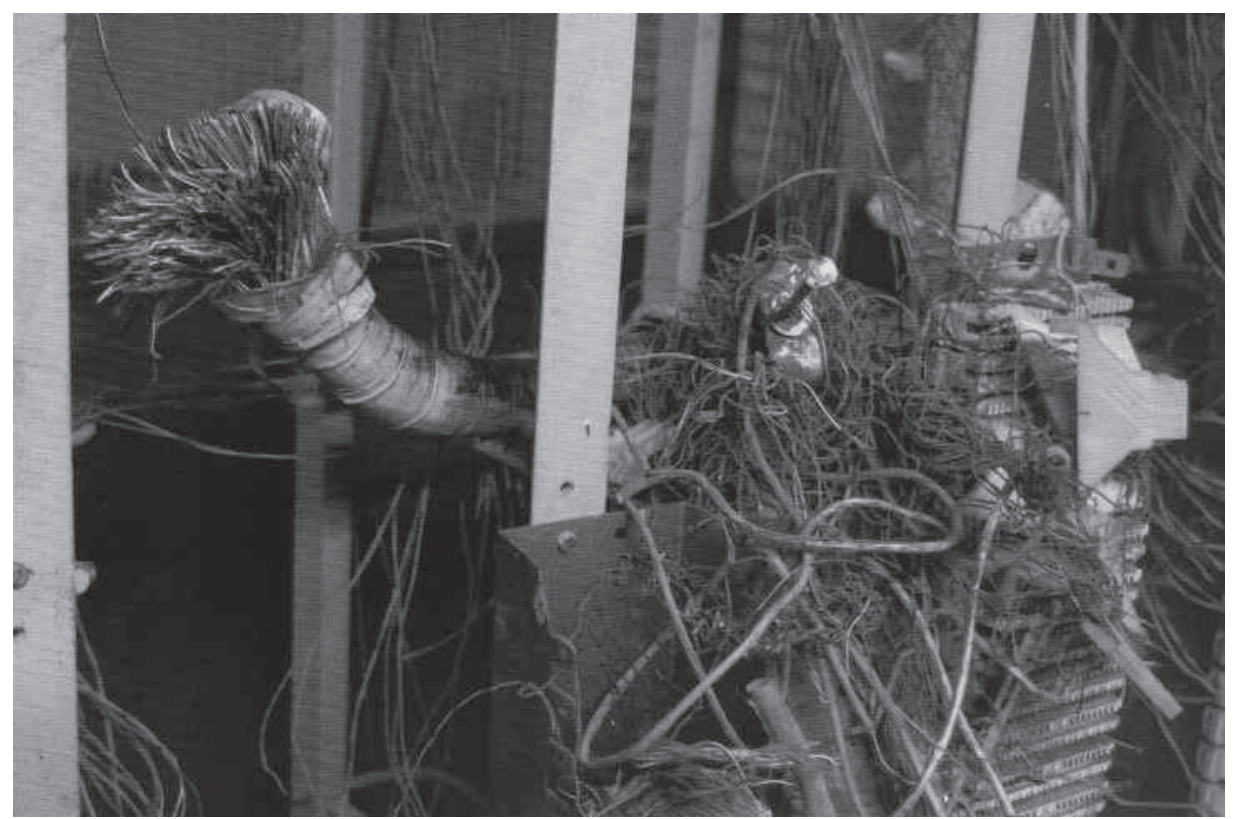

Imagen interior del catálogo Tentativa Artaud. 2008.

formalizada en "Proyecciones en dif. esc.:" con la noción de tra(u)ma, término en el que laten tanto la idea de trama gráfica como la de trauma, y que cobrará su mayor grado de intensidad con el elemento sin duda más desgarrador que incorpora la obra.

El año 1976 el DEH es clausurado por los agentes represores de la dictadura y convertido primero en un recinto de la DINA y posteriormente en una dependencia de la CNI, específicamente una central de vigilancia telefónica dedicada a labores de espionaje (Figura 4). En principio, diríase que el establecimiento de un cuartel de vigilancia (es decir, una institución dedicada al "archivo de la política insurreccional") constituye una paradoja siniestra para una obra que hace del archivo del trauma un eje de trabajo primordial. Pero no hay algo así. Los agentes represores instalados en ese cuartel de vigilancia no sabían que poco antes, en ese mismo espacio, la obra de Kay intentaba crear un "espacio de resistencia psíquica" contra la dictadura. No sabían tampoco, y esto es lo decisivo, que sus macabras operaciones estaban siendo procesadas espectralmente por el archivo de Tentativa Artaud. Por esta razón, no cabe hablar aquí tanto de una paradoja, en tanto era ya inherente a la virtualización de la Tentativa el contener dentro de ella a una narrativa (como la dictatorial) que no buscaba sino consumar la historia y dar por clausurada cualquier posibilidad de narración alternativa.

Hay, en efecto, toda una poética de lo virtual y el diferimiento que se ensaya aquí, una premisa explícitamente apuntada por Kay en múltiples pasajes. En Circuito cerrado, por ejemplo, y refiriéndose al retardo en la publicación de los poemas tempranos 
FIGURA 5

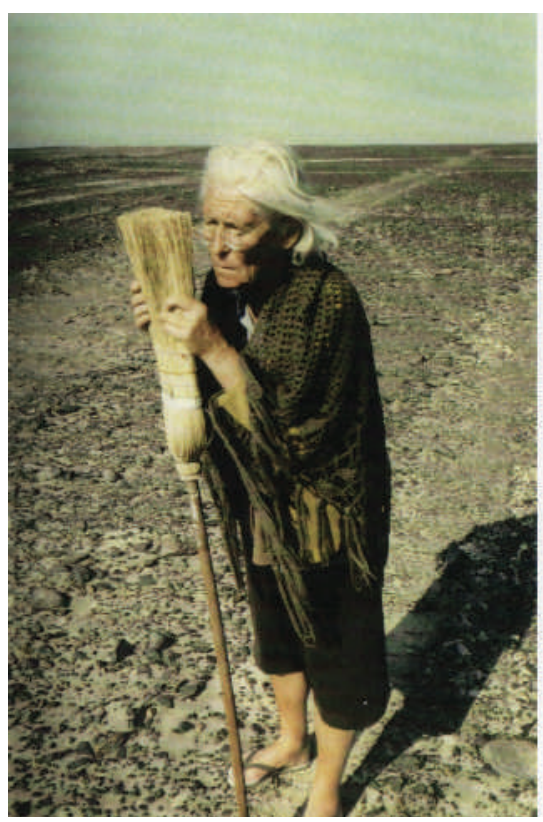

Imagen interior del catálogo FUERA DE ESCALA/ en los límites de las líneas nazca. Casa del Arte, Concepción, Chile, 2014.

(incluidas las Variaciones), dirá que "retirarse de la actualidad es la consecuencia de una estrategia poética (...)” (7), una que consiste en “(...) exponer lo irreal como virtud (...), entregar a la acción del tiempo lo que uno por sí mismo no logra despejar” (9). Importante es enfatizar que a esa práctica de retardo (Nachträglichkeit), no solo le será consustancial la virtualidad ínsita a la escritura, sino también esa particular concepción del tiempo que despliega Kay, en la que la catástrofe, como vimos, es cifra fundamental. Sic transit gloria mundi podría ser aquí una divisa clave, pues se trata, en efecto, de las lágrimas y la sangre de Cronos, del abismo del tiempo, nociones que circulan en toda la obra de Kay, y que no hacen sino exhortar al trabajo de la memoria y el atesoramiento. No por nada, en efecto, Kay tendrá por decisivos los poemas de Hölderlin sobre el abismo (Vom Abgrund nemlich) y Mnemosyne. No otra cosa, asimismo, fundamentará el rescate de los textos de Propercio o el sentido homenaje a María Reiche (Figura 5) y las líneas de nazca.

"Desde el abismo del tiempo" (Kay, Un matiz 12) 22 $^{22}$ de tal suerte, viene a despuntar toda una política de los despojos y la memoria, una política que, en la Tentativa Artaud, desplegará bajo la influencia de Vostell (Kay, Vostell s/n) un atesoramiento de diversos

22 Una cita en el mismo libro, extraída de Godard, resulta aquí crucial: "El mundo solo se nos da a conocer en tanto desaparece. ¿qué hemos de hacer aquí entonces, nosotros los vivos, mas no vivir, sino imitar la resurrección?” (Kay, Un matiz 30) 


\section{FIGURA 6}

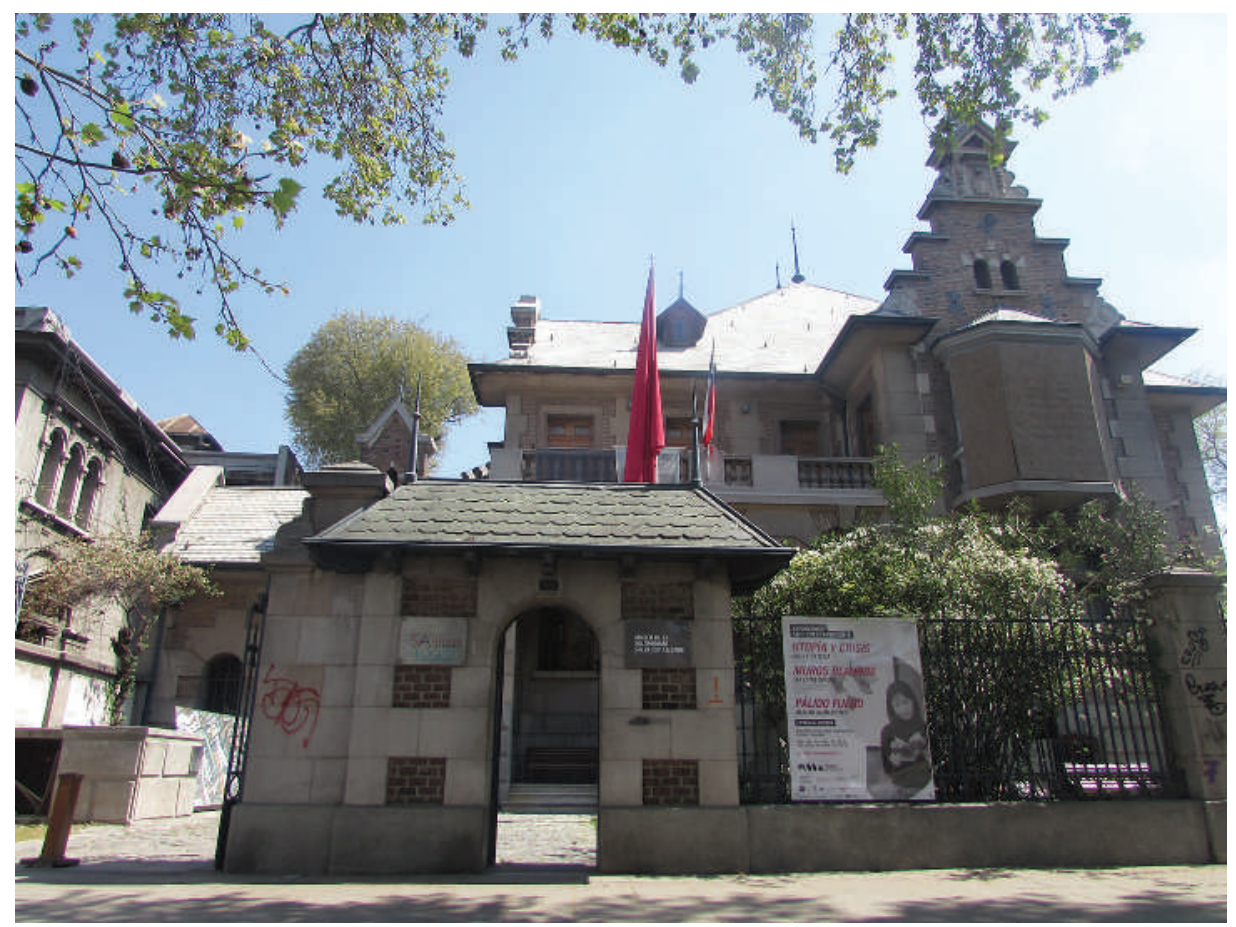

Museo de la Solidaridad Salvador Allende, 2017.

materiales y residuos, y, complementariamente, una práctica de atesoramiento de los soportes $^{23}$. Pues, en efecto, debe juzgarse como elemento esencial de la obra no solo la salvaguarda de las corporalidades y objetos que se desplegaron en 1974, sino también la absorción de la siniestra trama dictatorial que imponía un nuevo marco de lectura histórica. Los agentes opresivos de la dictadura archivaban la política subversiva, pero ese mismo archivo entraba en pugna con una obra, la Tentativa, que aguardaba en silencio una nueva narrativa en la que insertarse. Actualmente, es menester indicarlo, otra institución atesora la memoria abismal de todos esos desplazamientos que pensó, sotto voce, la Tentativa Artaud (Figura 6).

Política de los despojos, entonces, como metapolítica que tensiona los legados y la herencia, en busca de nuevas reorganizaciones sociales. En Circuito cerrado, Kay insistirá, hablando sobre las Variaciones, sobre la tarea de "investirse de irrealidad", tarea que tendría por propósito "detectar el latir de las edades" (22). Pero ya un poco

23 Por ese motivo, sugerimos anteriormente, es posible matizar la vinculación entre Fluxus y Kay. Aunque no suscribimos su exégesis general, Jean Clair ofrece una crítica de la obra de Beuys bajo la idea, a nuestros propósitos significativa, de un "culto a las reliquias" (Clair 76). 
antes, y de forma elocuente con lo aquí señalado, ha indicado que es necesaria "la luz pública que (...) origine la gracia que (...) reorganice al individuo” (21). Por su parte, y refiriéndose al trabajo de Dittborn, aunque igualmente decisivo aquí, en "Proyecciones en dif. esc.:", luego de interrogarse "cuáles son los facta de la historia" y "qué incidentes debe encuadrar", Kay señalará que el trabajo con los dispositivos de determinación técnica constituye una operativa con la cual "se incita, trama y concita su inédita edición (...)” (235.). Pasajes significativos, creemos, en la medida en que permiten apreciar en la política de los despojos que despliega la Tentativa precisamente la búsqueda de una nueva edición histórica. Desde el abismo del tiempo, por tanto, una memoria política indisociable de una política de la memoria, una que busca abrir grietas para "ajustes de sentido" y para nuevas o "inéditas" formas de memoria: Elaboración del trauma mediante la elaboración de nuevas tramas.

\section{Referencias}

Artaud, Antonin. "On the cinema”. Collected works III. London: Calder \& Boyars, 1972. 59-84.

---. “The Theatre and its Double”. Collected Works IV. London, John Calder, 1999. 1-110. Benjamin, Walter. Das kunstwerk im Zeitalter seiner Reproduziertbarkeit. Berlin, Suhrkamp, 2012.

---. Parque central. Trad. Ronald Kay. Santiago, Metales Pesados, 2014.

Bredekamp, Horst. Der Bildakt. Berlin, Klaus Wagenbach, 2015.

Canal Centro Cultural La Moneda. "Conversaciones con Ronald Kay- Capítulo 1" (2012). https://www.youtube.com/watch?v=_OcG3OKqwW4\&t=32s. Fecha de ingreso: 10 de enero 2018.

Clair, Jean. De immundo. Madrid, Arena libros, 2007.

De la Cruz, Catalina y Kay, Ronald. FUERA DE ESCALA/ en los límites de las líneas nazca. Casa del Arte, Concepción, Chile, 2014. Medio impreso.

Déotte, Jean-Louis. ¿Qué es un aparato estético? Benjamin, Lyotard, Rancière. Santiago, Metales Pesados, 2012.

Derrida, Jacques, De la gramatologie. Paris, Les Éditions de Minuit, 1967.

Didi-Huberman, Georges. "Entrevista”. La Nación, Buenos Aires, 31 de octubre de 2014. El techo de la ballena. Ruiz, Raúl, dir. Act. Willeke van Ammelrooy, Jean Badin, Fernando Bordeu. DVD. Archivo Ruiz-Sarmiento (PUCV), 1981.

Galende, Federico. Filtraciones I. Conversaciones sobre arte en Chile (de los 60' a los 80'). Santiago, Arcis/Cuarto Propio, 2007.

---. Filtraciones II. Conversaciones sobre arte en Chile (de los 80' a los 90'). Santiago, Arcis/Cuarto Propio, 2009.

---. Filtraciones III. Conversaciones sobre arte en Chile (de los 90' al 2000). Santiago, Arcis/Cuarto Propio, 2011. 
Kay, Ronald. Circuito cerrado. Los inéditos de la década de los 60. Glosas. Santiago, Nómade/La calabaza del diablo, 2001.

---. “Clío. Origen gráfico del continente como Nuevo Mundo; episodios de su registro visual". Pensar \& poetizar 8/9 (2010). 29-51.

---. Deep freeze. Los inéditos de la década de los 60. Santiago, Nómade/Be-uve-dráis, 2000.

---. Del espacio de acá. Señales para una mirada americana. Santiago, Nómade, 2009.

---. “Die Rhetorik des Blickes”. Tesis. Universität Konstanz, 1972.

---. "Introducción a la mortalidad”. Pensar \& poetizar 10 (2012). 23-33.

---. "La mirada de lo ausente". Pensar é poetizar 13 (2016). 35-85.

---. "Lecciones de analogía. FUERA DE ESCALA/en los límites de las líneas de Nazca". Pensar \& poetizar 12 (2015). 33-55.

---. Lorenzo Berg, un origen. Santiago: Consejo de Monumentos Nacionales de Chile, 2014.

---. "Poemas". Anales de la Universidad de Chile 137 (1966). 141-152.

---. "Proyecciones en dif. esc". El revés de la trama. Escritura sobre arte contemporáneo en Chile. Comp. Daniela González Maldini. Santiago, Universidad Diego Portales, 2010. 214-236.

---. "Rewriting”. Manuscritos 1 (1975). 25-32.

---. Tentativa Artaud. Santiago, Metales Pesados, 2008.

---. Un matiz más blanco de lo pálido. Santiago, Nómade, 2012.

---. Variaciones ornamentales. Santiago, Universidad Diego Portales, 2009. Medio impreso.

---. Vostell. Santiago, 10a Bienal de Video y Artes Mediales, 2011.

Krauss, Rosalind. "La escultura en el campo expandido". La posmodernidad. Ed. Hal Foster. Barcelona, Kairós, 1986. 59-74.

Macchiavello, Carla. "Vanguardia de exportación: la originalidad de la "Escena de avanzada' 'y otros mitos chilenos"'. AA.vv. Ensayos sobre artes visuales. Prácticas y discursos de los años 70 y 80 en Chile. Volumen I. Santiago, Lom/Cedoc, 2011. 85-117.

Marchant, Patricio. "Discurso contra los ingleses". Escritura y temblor. Eds. Pablo Oyarzún y Willy Thayer. Santiago, Cuarto Propio, 2000. 27-31.

Lihn, Enrique. Textos sobre arte. Eds. Adriana Valdés y Ana María Risco. Santiago, Universidad Diego Portales, 2008.

Oyarzún, Pablo. "Arte en Chile, de veinte, treinta años". Arte, visualidad e historia. Santiago, Universidad Diego Portales, 2015. 213-259.

Rancière, Jacques. Mallarmé. La política de la sirena. Santiago, Lom, 2015.

Richard, Nelly. Crítica y política. Santiago, Palinodia, 2013.

---. Márgenes e instituciones. Arte en Chile desde 1973. Santiago, Metales Pesados, 2014.

Rojas, Patricio. Motivo de yeso. Santiago, V.I.S.U.A.L. y Espacio Siglo Veinte, 1978.

Sebald, W. G. Sobre la historia natural de la destrucción. Barcelona, Anagrama, 2015. 
Stiegler, Bernard. "Derrida y la tecnología: la fidelidad en los límites de la deconstrucción y la prótesis de la fe". Jacques Derrida y las humanidades. Coord. Tom Cohen. México, Siglo XXI, 2001. 303-341.

Thayer, Willy. "El Golpe como consumación de la vanguardia". El fragmento repetido. Escritos en estado de excepción. Santiago, Metales Pesados, 2006.

Vostell, Wolf. Vostell. Santiago, V.I.S.U.A.L. y Galería Época, 1977. 